\title{
The sixth generation of knowledge management - the headway of artificial intelligence
}

\author{
Andrea Bencsik \\ Department of Management, University of Pannonia, \\ Hungary \\ bencsik.andrea@gtk.uni-pannon.bu \\ ORCID 0000-0001-8204-3706
}

\begin{abstract}
The intertwining of knowledge management and artificial intelligence is no longer a surprising fact today. However, very few studies deal with the development of a system that is clear in details and at the same time summarising, which proves the theoretical and practical validity of connection points. The aim of the theoretical research is to develop a framework that, starting from the business model, with the help of the synergy of knowledge management (KM) and artificial intelligence (AI), outlines a solution to predict future innovation success, ensuring the feasibility of the strategy with the right managerial decisions. The study briefly touches upon the importance of the strategy, then, based on the development path of KM, presents the close mutual interaction between $\mathrm{KM}$ and $\mathrm{AI}$ and the AI tools applicable to each step of KM. The research result is a model for predicting successful innovation that, supported by artificial intelligence in the knowledge development step of knowledge management, provides the basis for the right managerial decisions to ensure the achievement of strategic goals. The practical application of the model in the everyday life of companies supports managerial foresight, decisions about innovative investments which influence organisational success.
\end{abstract}

Keywords: absorptive capacity, innovation, knowledge management, managerial decision, strategy.

JEL Classification: L00, L21, M1, M15, M21, O32, O33, O34

\section{INTRODUCTION}

In a changing business environment, the development and operation of knowledge management (KM) systems is of critical importance for the adaptability and competitiveness of companies. It plays a prominent role in company processes that seek synergies between data, the processing capability of information technology and the creative and innovative skills of people (Sanzogni et al., 2017). Outstanding among these company processes are the development of strategy and the making of 
decisions necessary for successful implementation (Forgang, 2015). Thanks to the accelerated pace of development in the recent years, the supporting tools and informatics solutions used in the steps of the knowledge management process today go well beyond the possibilities formulated in earlier phases of the KM development (Rhem, 2017).

The dynamic development of information and computer technologies (microprocessors, satellite technologies and the Internet) means that in recent years we have been talking about artificial intelligence (AI) more and more as the methods applied in everyday organisational practice (Upshall, 2019; Pushpa, 2019). They are organic elements of the business model of many organisations and a key strategic component of the global plans in various sectors. These technical solutions make it possible to follow the continuous change and development of information and knowledge, to store huge databases and large amounts of information, to share knowledge rapidly, thus ensuring the right of access of those involved. As a result, it becomes possible for the day-to-day work of organisations, management decisions and the development of strategy to be based on the up-to-date market information. Although studies to date have not provided specific survey data on the impact of supporting new technologies upon organisational success, all organisations are trying to keep pace with technological advances to the best of their ability. At the same time, the relationship between technical and technological development needs and the tools and conditions required for the management of organisational knowledge is not clear. By opening up new areas of application, artificial intelligence has an impact on organisation performance, including the implementation of steps in the knowledge management process (Lemaignan et al., 2016). Greater efficiency, better productivity, innovativeness and reliability are in connection with a higher level of acceptance of artificial intelligence, although this positive innovation is not heartily welcome in all the areas (Shabbir \& Anwer, 2015).

Based on this knowledge, the research questions were formulated, which the study endeavours to answer on a theoretical level. How can the development of technological solutions support the steps of the KM process? Through what phases, by which tools can strategic solutions be best supported? How can more developed technological solutions meet the needs of new business models - through acquisition, distribution, improvement and application of knowledge? Based on the responses to these questions, the research aims to create a new logical model that was not in the focus of previous research. The model provides an opportunity for managers to make the right decisions by estimating the success of investments that ensure innovation. After the literature review and the system of relationships presenting the framework of thinking, the two most relevant organisational areas (KM - AI) in their symbiosis are presented. Following this, by observing the steps of the KM process, highlighting the area of knowledge development and innovation, a possible AI-supported solution is presented that fundamentally influences strategy. The study ends with the discussion of managerial decisions that can be made based on this new model, conclusions, and limitations of the research.

\section{LITERATURE REVIEW}

\subsection{Theoretical model}

In order to make the logic of our further thinking comprehensible, the network of relationships will be outlined (see Figure 1), which has already been formulated in the Introduction, and the following chapters it will show the fully described connection between KM and AI, building upon the strategic decisions deducible from the organisational operating model. 


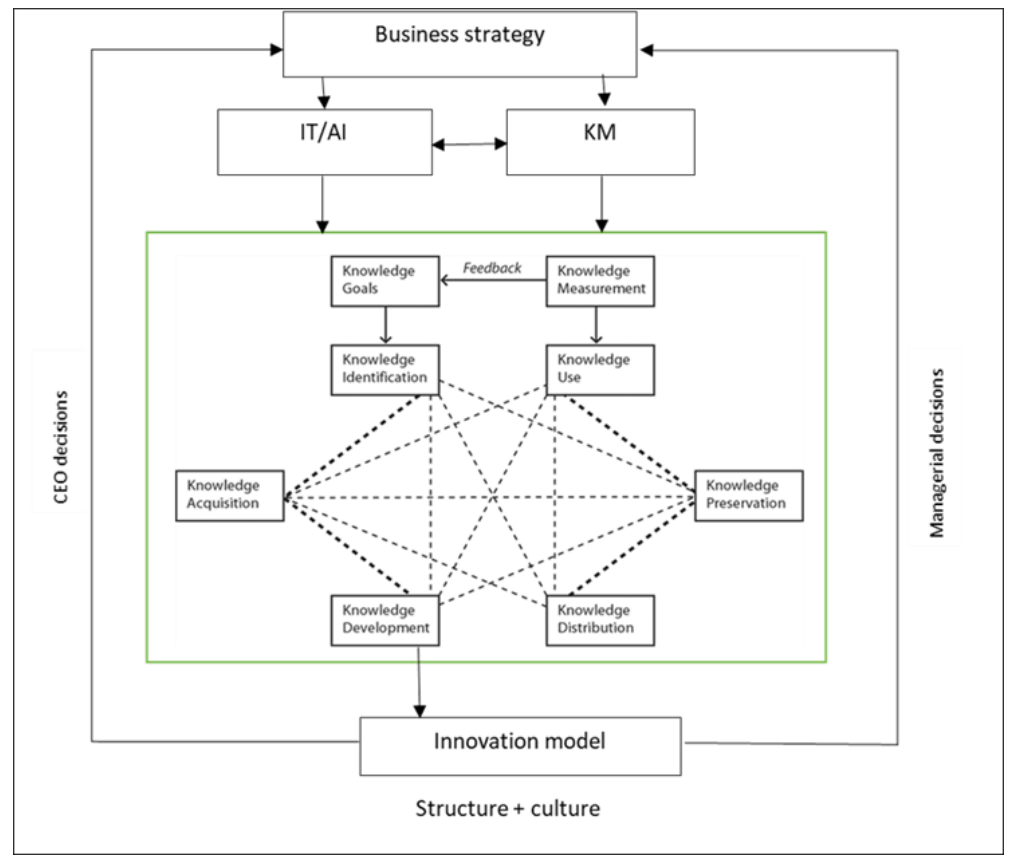

Figure 1. Framework for the symbiosis of knowledge management and artificial intelligence Source: based on Probst et al. (2006) model own construction.

As the figure above shows, strategic objectives and the conditions and decisions necessary for them can be deduced from the business model. The study does not discuss the relationships that are in connection with organisational structure, culture and other organisational processes, but it should be kept in mind that, in reality, their impacts on the symbiosis of $\mathrm{KM}$ and $\mathrm{AI}$ cannot be neglected.

\subsection{Strategy}

The use of the knowledge necessary for the implementation of the organisational strategy that ensures the functioning of the business model is determined by the knowledge management strategy of the organisations. Questions to be answered in the development of a knowledge management strategy include which characteristics of it are of strategic importance, the knowledge components of which processes or products represent the most added value, and how the competitiveness creating power of knowledge management strategy can be demonstrated. The answers vary depending on the organisation's market position, the status of industry and the available resources (Syed, 2017).

An integrated approach to knowledge management assumes that the organisation is aware of the competences necessary for the implementation of the strategy and provides the infrastructure to acquire them. Organisational culture, operational processes and organisational structure as well as supporting human and information systems are parts of organisational infrastructure. Of these, we will only deal with the importance of informatics later on.

In the next phase of the theoretical model, it is necessary to explore the relationships between KM and AI. First, we will discuss the importance of artificial intelligence in general, and then its close interaction with KM will be outlined. 


\subsection{Artificial Intelligence}

Artificial intelligence is one of the most fashionable terms in various segments of the economy, along with actually being a research area that has existed for decades (Haenlein \& Kaplan 2019).

$\mathrm{AI}$ evolved into a multidisciplinary science at the end of the 1980s and the beginning of the " 90 s that involves expert systems, neural networks, robotics, natural language processes, speech recognition and virtual reality (Ertel, 2017).

Artificial intelligence offers a number of advantages for both citizens, companies and the whole society, provided it represents ethical and sustainable values. In order to be able to take full advantage of the opportunities offered by artificial intelligence, both individuals and organisations face a serious challenge (Cockburn et al., 2018). However, at current stage of ICT development and implementation of AI in business processes these challenges should be tackled as they provide new opportunities for economic growth (Bilan et al., 2019), particularly via HRM improvement (Balcerak \& Woźniak, 2021), and competitive advantages achievement due to the new possibilities of knowledge acquisition, knowledge sharing, and knowledge application. (Wijaya \& Suasih, 2020). Skills and competences need to be improved that were only partially or not needed before. A common goal is to foster the ability of organisations to innovate, while keeping in mind the development of an ethical and reliable artificial intelligence.

Artificial intelligence provides individual and groups with opportunities and power to achieve creativity and productivity growth at all levels of the organisations and makes it possible to measure outcomes. It helps organisations achieve their business goals in several of their activities more easily and increase their profitability, thus providing space to improve their competitiveness, cut costs, increase security and provide data on a continuous basis (Kazuo, 2017). These opportunities strengthen solutions applicable in the steps of the knowledge management process.

\subsection{Knowledge Management}

Knowledge management, like artificial intelligence, is a multidisciplinary field. KM involves psychology, epistemology, and cognitive sciences. Its aim is to enable people and organisations to cooperate, and to distribute, develop, use and recycle knowledge (Bencsik, 2016). The understanding of $\mathrm{KM}$ influences productivity growth, the increase of innovation and the enhancement of both individual and organisational knowledge.

To understand the sixth generation of KM indicated in the title, a brief historical overview is necessary. Although many have attempted to demarcate the phases of development and historical formation in different ways, the most notable of these is Anklam's classification, the rethought process of which is described below (Bencsik et. al, 2018).

\section{Generations of $\mathrm{KM}$}

The characteristic feature of the first era of evolution is that it focuses on the technology of knowledge creation and formation. Everywhere during this period, the development and application of information technology opportunities were identified with the operation of knowledge management (Anklam, 2009). Later it turned out that to explore, integrate and transfer hard-to-find dimensions of tacit knowledge the application of information technology alone is enough.

The main feature of the second era is the recognition and conscious management of the difference between knowledge-based and experiential, problem-solving knowledge. The issue of human resource management comes into focus when seeking to answer how to create the conditions to establish an organisational atmosphere and culture that supports knowledge distribution, how to usefully operate organisational groups - primarily knowledge communities, combining all this with the need for the expression of human knowledge and intellectual capital to become as real as possible. The understanding 
of this issue importance leads to creation of favouring atmosphere of talents management, their engagement and retaining (Bilan et al., 2020; Masoomzadeh et al., 2019) as well as improvement of knowledge sharing process aiming at workplace innovation development (Arsawan et al., 2020). The second generation already highlights the difficulties of the codification of tacit knowledge. Due to its personal nature, tacit knowledge has parts that cannot actually be taught. The typical methodology of the era is benchmarking, which helps to map the above mentioned gaps, with support from leadership and knowledge conversion.

In the third era, thinking about knowledge goes beyond information technology, individuals, and even organisations, and appears as a network. The purpose of third generation knowledge management in general is nothing else than to systematically improve the organisation's ability to mobilise knowledge in order to increase performance. The free flow, growth and empowerment of knowledge can be achieved through knowledge care and application, primarily with the help of network building and the establishment of knowledge communities (Zamir, 2019). It is important to create an environment that facilitates the unfolding of knowledge. This is the essential message of third generation (post-Nonaka) knowledge management.

Further considering Anklam's categorisation, the further phases of development, such as 4th and 5th steps are also present in the life of organisations. The fourth generation focuses on the consideration of knowledge as a capital factor and seeks to quantify it - thus strengthening the needs emerging in the second phase, while phase 5 discusses the relationship between company competitiveness and innovation. As can be seen, developed economic systems in the fourth and fifth generation of knowledge management search for an expression of the value of human resources that is increasingly being raised in company practice (Silva de Garcia, 2020). At the same time, it can be seen that radical, conceptual advances have taken place in the first three generations, and, since then, the possibilities of development, the consideration of human resources as a capital and its quantification and organisational application have come to the fore, constantly emphasising the need for innovation (Bencsik \& Filep, 2016).

\section{The possible future of $\mathrm{KM}$}

The above mentioned eras have developed one after the other as a natural consequence of expert thinking, organisational practice and technological development, but all of the eras listed are present side by side at different levels of development in company practice. Successful initial knowledge management actions or the operation of systems is not always conscious, but the direction of ambitions indicates right decisions. The question is: what is the next step of evolution? How does the appearance of artificial intelligence solutions influence the future of knowledge management in organisational life? If we think through previous phases of the evolution, we can imagine two possibilities. In the first case, evolution although continuing on a higher level - actually returns to the initial steps and the cycle restarts. That is, the omnipotence of IT will regain its dominance, and the rule of artificial intelligence will play the title role (sometimes swapping the significance of goals and tools), sending the results and focuses of previous evolutionary phases into the background. Just as knowledge management solutions were often identified with a well-developed IT system in the first phase, now the attention is drawn to technological solutions once again, and artificial intelligence as a higher level of IT opportunities is put in the focus of thinking. And then, evolution begins again, following the same path as in previous periods of development, but at a higher level (Ruparel, \& Choubisa, 2020).

The other way is to become capable of managing possibilities offered by artificial intelligence properly, and assign to the steps already taken the supporting solutions that elevate the organisational practice of the knowledge management process to a higher actual level. This means that each step of a $\mathrm{KM}$ process can be assigned solutions supported by artificial intelligence that help you take the necessary intervention or solve the task arising in the actual phase faster, more efficiently and more successfully 
(Alani et al, 2019). Currently, none of the mentioned solutions are discussed in the literature, and there is a lack of professional recommendations that summarise the AI solutions that best support the steps of the $\mathrm{KM}$ process at the system level. Some of the methods that can be used for each step of the KM process are mentioned below as examples.

\section{AI SOLUTIONS THAT SUPPORT KM PROCESS STEPS}

\subsection{Probst model and AI}

The possible supporting tools presented as an example are guided through the logic of the Probst's (2006) model below. The model, which already played a central role in Figure 1 is shown in Figure 2.

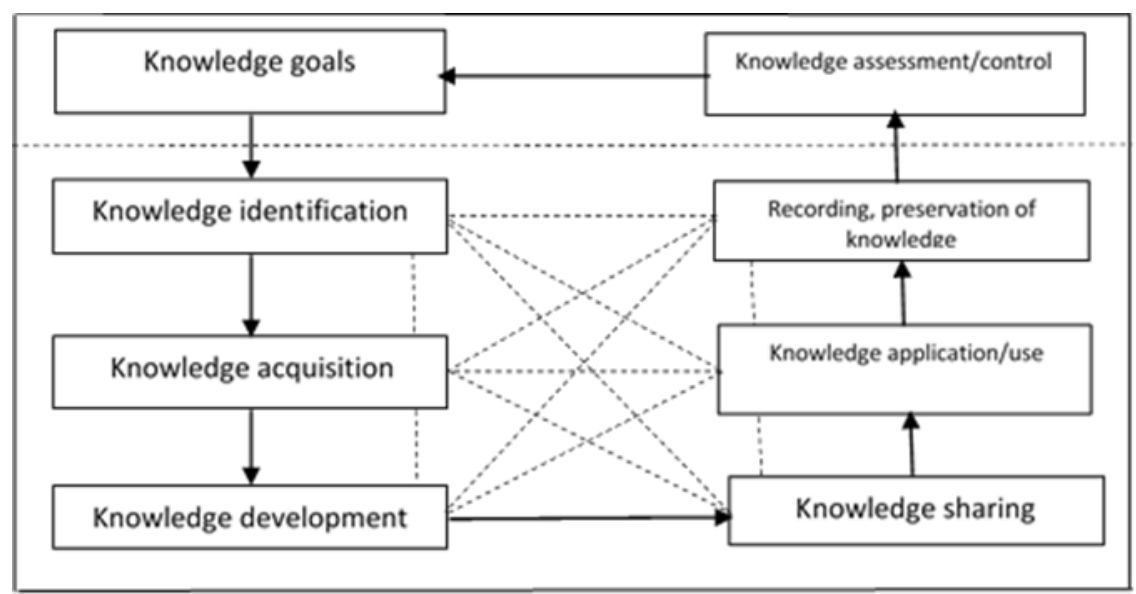

Figure 2. Probst's model

Source: Probst et al, 2006.

Defining knowledge goals: e.g. a three-screen solution for "SAP Digital Boardroom" digital decision support. Systems that support strategic decisions integrate rules and logic into the processing of large data sets through artificial intelligence (Marks, 2016). Relevant information can be extracted from accumulating and opaque data masses that make decision making easier at different organisational levels. Thus, aligning strategic goals with the requirements of the knowledge management strategy becomes easier. Certain decision making situations may as well be automated and also be able to make predictions.

In the case of knowledge identification, a teachable artificial intelligence system can be developed, which can be used to customise access to company knowledge base. Corporate knowledge base can be kept up-to-date, in which available internal knowledge holders can be found for actual strategic goals, or the system can be made suitable for searching from external resource as well, e.g. applying SAP HANA. After loading necessary information, the system, through learning from the answers given to the questions, becomes able to develop an organisational knowledge base that is then automatically enhanced with each newly emerging elements of information (Liu et al., 2020).

In the case of knowledge acquisition, through formal and informal channels, we can obtain useful information that leads to the people whose knowledge we need. Help in this case is biometrics. It is suitable for giving support, based on competences and human characteristics, e.g. the selection of workforce or experts. The role of AI here is to process enormous statistical data sets based on given parameters (Jaina et al, 2016). 
The knowledge development step is a factor that directly influences competitiveness. In neural networks, learning through patterns is typical, when we want to extract adequate information from the generally large data sets, and so modify system behaviour, e.g. using WATSON. Often, employees themselves generate the necessary knowledge - the development of ideas, models, competences, processes, etc. - and the acquisition of new knowledge necessary for this (Kuo, 2019).

Knowledge sharing is a critical sub-process of the KM cycle, and a condition of the organisation's survival. Cooperative robots (cobots for short) are designed to work beside humans as their direct coworkers, exempting them from repetitive, stressful or dangerous operations. It is an increasingly common solution of knowledge distribution that machine intelligence learns from another AI via the Internet. For example, on a production line, it is easier to master the new workflow than program the machines one by one. Cobots can connect to artificial intelligence systems that run on background systems or in the cloud, so, instead of programming, they can easily be taught new workflows under the auspices of knowledge distribution (Seriani et al., 2018).

The phase of knowledge preservation includes the action of recording, systematisation, storing and refreshing. Knowledge-based systems store describable explicit forms of knowledge in a problem area, or they are used to store expert knowledge that enables the management of a narrower issue. The engine of knowledge-based systems is provided by inference systems. For instance, a central feature of case-based reasoning (CBR) is to infer past solutions (real situation descriptions and interpretations) to solve present a present problem. The system is capable of self-teaching, of learning from experiences, providing it receives feedback. So it is not only able to store information, but in a given situation, it makes new searches easier, simpler and shorter (Lesniak \& Zima 2018).

Possessing knowledge does not provide results in itself, but its application does. The user-friendly nature of the technology that supports access to knowledge helps employees with knowledge use. As an example, using text-based AI can increase process efficiency, problem solving speed, or the quality of customer service. For example, they can be used especially well in the case of financial institutions and contact centres. In addition to an intelligent search function that can be applied to exact terms or even complex sentences, the system is able to propose emails or chat responses, to visualise data sets, or the intelligent escalation can help make bottleneck processes more efficient (George et al, 2017).

When measuring knowledge, the enforcement of the system approach and the review of relationships are essential. IoT and/or content analysis can help. Features related to human resources mostly belong to the invisible category in companies' balance sheets, yet it was not correct to exclude them when evaluating performance as an organisation's value lies in organisational members, in the mind of humans, and this invisible capital is worthless without humans, or perhaps it does not even exist (Mittal et al, 2019).

In order to increase transparency, Table 1 below summarises the best-known tools already in practical use, which are merely examples of support solutions that can be used in individual steps. 
Table 1

Possible AI support for KM steps

\begin{tabular}{|c|c|c|c|}
\hline \multicolumn{3}{|c|}{ Digitisation areas } & \multirow[b]{2}{*}{ Artificial intelligence solutions } \\
\hline $\begin{array}{c}\text { Building } \\
\text { blocks of KM }\end{array}$ & Processes & $\begin{array}{l}\text { Methodological background, } \\
\text { management tool box }\end{array}$ & \\
\hline $\begin{array}{l}\text { Strategic } \\
\text { knowledge } \\
\text { goals }\end{array}$ & $\begin{array}{l}\text { Setting normative, strategic and } \\
\text { operative goals - knowledge } \\
\text { organisation, preparation, } \\
\text { qualification of directions of } \\
\text { innovation, creation of access } \\
\text { opportunities }\end{array}$ & $\begin{array}{l}\text { Network building } \\
\text { Decision models } \\
\text { Brain storming }\end{array}$ & $\begin{array}{l}\text { OCR (optical character recognition), } \\
\text { text generation from data, deep } \\
\text { learning, identity management, Digital } \\
\text { Boardroom, probabilistic networks, etc. }\end{array}$ \\
\hline $\begin{array}{l}\text { Knowledge } \\
\text { identification }\end{array}$ & $\begin{array}{l}\text { Comparison of existing } \\
\text { knowledge and knowledge } \\
\text { required to implement a strategy }\end{array}$ & $\begin{array}{l}\text { Benchmarking, Knowledge map, } \\
\text { Competence map, } \\
\text { databases, } \\
\text { data storages, } \\
\text { document management systems }\end{array}$ & $\begin{array}{l}\text { Machine learning (self-teaching } \\
\text { system), content-based semantic search, } \\
\text { smart response suggestion system, } \\
\text { keyword recognition and self-reflexion, } \\
\text { Big Data solutions, cloud-based service }\end{array}$ \\
\hline $\begin{array}{l}\text { Knowledge } \\
\text { acquisition }\end{array}$ & $\begin{array}{lcc}\text { Acquisition of } & \text { missing } \\
\text { knowledge from } & \text { external } \\
\text { and/or internal resources }\end{array}$ & $\begin{array}{l}\text { Company records, learning, } \\
\text { competitor monitoring, market } \\
\text { information, Peer Assist, } \\
\text { Lessons learned, After Action } \\
\text { Review, etc. }\end{array}$ & $\begin{array}{l}\text { OCR, text analysis, biometrics, chatbot, } \\
\text { content-based semantic search, text } \\
\text { mining, competitor intelligence (CI), } \\
\text { language translators, speech recognition } \\
\text { (hidden Markov models), Attract, } \\
\text { Onboard }\end{array}$ \\
\hline $\begin{array}{l}\text { Knowledge } \\
\text { development } \\
\text { /Knowledge } \\
\text { creation }\end{array}$ & $\begin{array}{l}\text { Combining, supplementing, } \\
\text { updating and refreshing existing } \\
\text { and acquired knowledge }\end{array}$ & $\begin{array}{l}\text { Learning, e-learning, follow-up, } \\
\text { brain storming, talent programs, } \\
\text { training and career plan, } \\
\text { development programs, } \\
\text { language teaching, building } \\
\text { professional communities, life } \\
\text { long learning, blended learning }\end{array}$ & $\begin{array}{l}\text { Follow-up systems, complex learning- } \\
\text { teaching systems, chatbot, multi-agent } \\
\text { intelligent tutoring system, } \\
\text { virtualisation, MOOC (Massive Open } \\
\text { Online Courses), thinking, consulting } \\
\text { artificial intelligences }\end{array}$ \\
\hline $\begin{array}{l}\text { Knowledge } \\
\text { distribution }\end{array}$ & $\begin{array}{l}\text { Dissemination of the necessary } \\
\text { knowledge to all stakeholders, } \\
\text { information distribution }\end{array}$ & 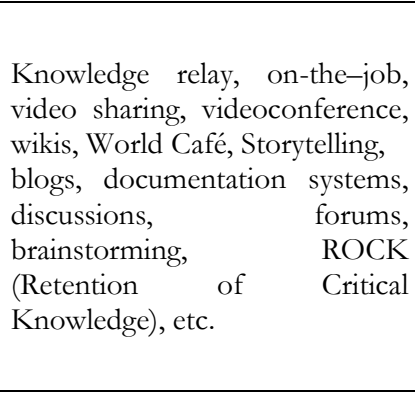 & $\begin{array}{l}\text { Virtualisation, speech recognition } \\
\text { systems, text analysis, Google Docs, } \\
\text { SharePoint, Social Learning, MyNet, } \\
\text { GrapeVINE, search tools supported } \\
\text { by artificial intelligence, company } \\
\text { intelligent escalation system, } \\
\text { DeepCoder, case-based reasoning, } \\
\text { artificial neural network, genetic } \\
\text { algorithm, agent approach, language } \\
\text { translators, speech recognition (hidden } \\
\text { Markov models) }\end{array}$ \\
\hline $\begin{array}{l}\text { Knowledge } \\
\text { preservation/ } \\
\text { recording }\end{array}$ & $\begin{array}{l}\text { Cases that have occurred, } \\
\text { typical problems solutions, } \\
\text { recording, necessary retrieval } \\
\text { and application of all past } \\
\text { information and knowledge }\end{array}$ & $\begin{array}{l}\text { Records, work instructions, data } \\
\text { storages, catalogues, paper- } \\
\text { based and electronic forms, } \\
\text { archive training and educational } \\
\text { materials, etc. }\end{array}$ & $\begin{array}{l}\text { Expert systems, DeepCoder, } \\
\text { knowledge-based system, case-based } \\
\text { reasoning, meaning-based search } \\
\text { programs, personal knowledge } \\
\text { management and content development } \\
\text { software }\end{array}$ \\
\hline $\begin{array}{l}\text { Use of } \\
\text { knowledge }\end{array}$ & $\begin{array}{l}\text { Acquired, up-to-date knowledge } \\
\text { application and integration into } \\
\text { work processes }\end{array}$ & $\begin{array}{l}\text { AAR (After Action Review), } \\
\text { Retrospect, lessons learned, } \\
\text { informal discussions, team work, } \\
\text { Big Data, etc. }\end{array}$ & $\begin{array}{l}\text { IoT (Internet of Things), content } \\
\text { management software, speech } \\
\text { recognition software, smart response } \\
\text { suggestion system, cobots, } \\
\text { virtualisation, speech recognition } \\
\text { (hidden Markov models) }\end{array}$ \\
\hline $\begin{array}{l}\text { Knowledge } \\
\text { evaluation / } \\
\text { measuring }\end{array}$ & $\begin{array}{l}\text { Comparison of the achieved } \\
\text { results and the strategic goals }\end{array}$ & $\begin{array}{l}\text { Analytical systems, measurement } \\
\text { and management model, } \\
\text { measurement breakdown } \\
\text { structures, etc. }\end{array}$ & $\begin{array}{l}\text { IoT (Internet of Things), content } \\
\text { management software, neural networks }\end{array}$ \\
\hline
\end{tabular}

Source: own construction. 


\subsection{Symbiosis of $\mathrm{AI}$ and $\mathrm{KM}$}

Knowledge is the essence of both KM and AI. AI provides the mechanism for machine learning, knowledge acquisition, knowledge processes and the use of knowledge for machines for task completion, and unleashes knowledge so that it can get to humans, to the improvement of the decision-making process. In fact, KM and AI are two sides of the same coin. Knowledge management makes the understanding of knowledge possible, while AI provides the competence to expand, use knowledge, to create new knowledge in a way that was unimaginable before (Haenlein \& Kaplan, 2019).

The relationship between KM and AI led to the development of cognitive computing. Cognitive computing applies computerised models to simulate human learning processes (Hanako, 2016). It includes deep learning artificial neural networks to use text/data mining, shape recognition, natural speech recognition, to imitate the operation of the human brain (Avdeenko et al, 2016). Cognitive computing leads to the synergy of KM and AI. The real challenge in this synergy is the establishment of a common system that can combine solutions to be applied using tools described in the Table 1 above or newer tools so that it can support the relationships between $\mathrm{KM}$ and $\mathrm{AI}$ and their synchronisation in a single common system.

Once the relationship between $\mathrm{KM}$ and $\mathrm{AI}$ is clear, the study endeavours to give a detailed description of a single step of the knowledge management process (knowledge development innovation), based on Probst's model described above. It illustrates the close relationships between the elements of the model and the complex processes lying in the background, the clarification of which can help to find applicable AI solutions.

\section{PRE-ESTIMATION OF INNOVATION}

\subsection{Innovation as a market need}

In today's rapidly changing environment, competitive organisations are able to operate as efficiently as possible in the present, with the available resources, while still seeking new opportunities and innovating with a focus on the future, thus ensuring long-term efficient operation (Mura, 2020; Teece, 2016). This strategic dual ability can be interpreted in terms of knowledge management and organisational learning by distinguishing exploratory and exploitative learning (Stachova et al., 2020).

Knowledge management means the training and further training of colleagues, self-study, selfeducation, joint brainstorming, the promotion of creative thinking, etc., and based on these, the developing of new solutions. Thus, within the framework of this KM step the idea arises: how can an organisation move forward in the market competition with innovative solutions?

All organisations have faced the fact that research and development is the costliest process, where constant questions arise: is it worth investing in development, what does it bring for the future, how much risk is right to take and worth taking, whether the market success, position can be achieved that the management set as a goal, etc. There is a need behind the questions for the innovation potential to be calculable or at least estimable in advance. On the one hand, the elaboration of this option helps in the case of organisational and strategic level decision on $\mathrm{R} \& \mathrm{D}$ processes, and on the other hand, provides an insight into similar features of competitors with the help of some kind of benchmark (Haar, 2018). In addition, managers get answers about the factors that qualify innovation potential, by the comparison of which it may be predicted which company will be truly successful in terms of its innovation activity and which one should not initiate research activity on an ad hoc basis. As this need has been present for years, there is no question that artificial intelligence can be of great importance in this area (Guban et al., 2019). The task to be solved is to establish a predicting method that, taking onto account the parameters 
influencing the organisation's innovation opportunities, is able to provide predictions based on the analysis of past experiences and the date from general world market trends (learning from them), thus supporting the management's decisions on future innovation investments. This solution has been elaborated at an algorithmic level and published in several studies by researchers, (Kasa, 2018) but it has not been noticed by organisational practice and IT developers. The question can rightly be asked: if the idea is given and the solution is elaborated in principle, why should it be dealt with here? The answer is detailed below.

\subsection{Qualification of innovation potential}

The theoretical model developed to measure innovation potential is based on an internationally accepted model, IMP3roveTM, which is based on a benchmark method. One of the world's most recognised consulting firms, A.T.Kearny and the German citadel of technological development, the Fraunhofer Institute developed it with support from the European Union (Cornell University, 2016). Since 2007, this benchmarking method has been the European standard for objectively measuring the innovation potential of small and medium-sized enterprises. Although the model includes advice and proposals for development opportunities, it does not have the features that would allow a forecast based on a multi-factor comparison (using artificial intelligence that meets today's needs), thus supporting a truly successful innovation operation, and protecting organisations from failure and unnecessary expenses. The model is built according to the following logic (see figure 3).

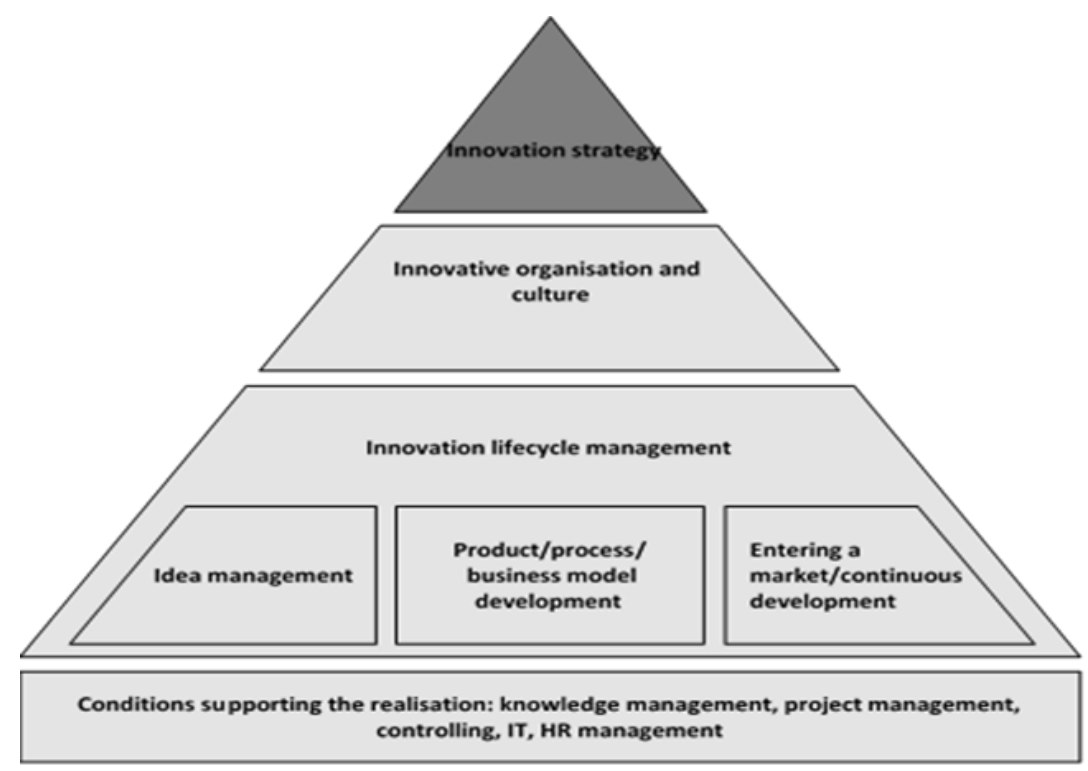

Figure 3. House of Innovation

Source: Engel et al, 2014.

The pyramid shown in the figure represents the factors, circumstances, characteristics, skills and expertise that influence and control innovation processes. 


\subsection{Organisational absorptive capacity}

The foundations for developing a new process is provided by the following theoretical consideration, which can be applied regardless of company size.

A special approach to organisational innovation is the so-called cognitive theory. It says that the ability of organisation to innovate depends primarily on their absorptive capacity. Absorptive capacity shows the extent to which an organisation is capable of utilising intra- and extra-organisational knowledge. According to Cappellari et al. (2019) this ability is of great importance for innovation. It depends on the knowledge, skills and competences of those working in the organisation, but is not the same as their mechanical sum. (Absorptive capacity is also of great importance for the building blocks the knowledge management system.)

The closeness of the relationship between the knowledge management system and the innovation processes is underpinned by the so-called Cedefop report (2012) which emphasises that employee knowledge, skills and competences characterise the organisation's learning potential, which is also called intellectual capital. This is the sum of knowledge accumulated within the organisation, which includes the knowledge and competences of employees, R\&D investments, software, marketing methods, work organisation, etc. Exploiting these can be seen as the success of innovation processes. As is well-known, intellectual capital consists of three further parts: human capital, structural (organisational) capital and relational capital (Cedefop 2012). Among other things, OECD defines the content of these components in its 2007 publication titled Human Capital. The details of the above are omitted, but Table 2 below shows the theoretical framework developed by Cedefop (Csizmadia, 2015).

Table 2

Elements of human, structural and relational capital

\begin{tabular}{|c|c|c|}
\hline \multicolumn{3}{|c|}{ Intellectual capital } \\
\hline Human capital & Structural capital & Relational capital \\
\hline Expertise & Organisational culture & Relationship with clients \\
\hline Practical experience & $\begin{array}{l}\text { Quality of cooperation and } \\
\text { communication within the organisation }\end{array}$ & Relationship with suppliers \\
\hline Social competences & IT infrastructure, software and hardware & Relationship with investors \\
\hline Motivation & $\begin{array}{l}\text { Knowledge transfer and knowledge } \\
\text { preservation }\end{array}$ & $\begin{array}{l}\text { Relationship with external } \\
\text { educational institutions }\end{array}$ \\
\hline Leadership competences & $\begin{array}{l}\text { R\&D infrastructure related to product } \\
\text { innovation }\end{array}$ & Acquisition of external knowledge \\
\hline $\begin{array}{l}\text { Personal knowledge and } \\
\text { competences }\end{array}$ & $\begin{array}{l}\mathrm{R} \& \mathrm{D} \text { infrastructure related to process } \\
\text { innovation }\end{array}$ & Social responsibility \\
\hline Continuous professional training & Organisational structure & The corporate image \\
\hline Training of new entrants & Organisational processes & $\begin{array}{l}\text { Relationship with other social and } \\
\text { economic participants }\end{array}$ \\
\hline Participation in higher education & $\begin{array}{l}\text { Application of info-communication } \\
\text { technologies }\end{array}$. & \\
\hline Participation in other education & Organisational forms that support learning & \\
\hline
\end{tabular}

Source: Forrás: Cedefop 2012:23.

The majority of surveys on innovation, in addition to technological developments and R\&D activities, mostly emphasise the importance of human capital, but the other two factors neglected, and the 
examination of the existing or possible relationships between them is almost completely missing (Deloitte, 2016).

Nowadays, when almost everything is about innovation, when it is one of the most important calling words among the tools of the Fourth Industrial Revolution, it is difficult to imagine that innovation potential is not one of the most highlighted research area, preferring the opportunities offered by artificial intelligence (Cockburn et al., 2018).

The models developed so far at the international level, in addition to the classification of the current situation, do not serve the possibility of forecasting. This fact shows complexity of the problem area and the difficulties in developing measurement methods. This challenge has motivated the thinking to develop a parameter system model that, combined with the opportunities provided by artificial intelligence already developed in theory, can provide a unique solution for companies.

\subsection{Shortcomings and opportunities}

Analysing the trends, it can be clearly seen that the traditional hard (technology- and product-based) innovations are being replaced by soft (services, social and organisational) innovations. In terms of research methods and tools, the emphasis is shifting to a qualitative direction, and the place of theorymaking is being taken over by case-based and empirical evidence-based research. In the past, typically the study of the past was widespread and also the examination of actual situations, by now a significant majority of studies predicting the future have taken place. The trend has also reversed in companies that are subjects of research: while in the past it was clear that large technology companies were the subject of studies, by now it has shifted towards the smaller ones, especially to the SME sector. Creative industries, smart solutions and most recently start-ups have emerged. The diffusion of innovations has been replaced by network-type innovation co-operations, which solutions clearly justify the needs of each step of knowledge management, treating the step of knowledge development as an especially important element in addition to knowledge distribution (Nepelski, \& Van Roy, 2018).

Seeing and perceiving these trends, it is worth turning from hard numerical factors towards the softer direction in terms of calculations, not only in terms of orientation, but also in terms of the factors that can be taken into account in that context. Thus, we will focus on the above mentioned IMP3roveTM examination method in the following, as it is the European standard at present. The calculation method covers a certain proportion of all three elements of intellectual capital, and in opposition to other models, it does not primarily focus on the importance of human capital. The dark colour elements of Table 3 below are the ones examined by the IMP3roveTM model (it does not make all of them fully quantifiable, but deals with them). Clear cells mean the factors the development of whose measurement will lead to the possibility of a more accurate forecasting of innovation ability and absorption capacity (Capellari et al., 2019).

Indications in the table show that the model takes each of the 3 elements of intellectual capital into account, but there are shortcomings in the case of all of them, especially in the area of human capital. Overall, the model accounts for approx. $40 \%$ of the possible factors, which indicates that the qualification of innovation ability - even in the case of this standard model - is less based on the assessment of intellectual capital. Rather, standard company numerical data dominate than R\&D expenditures, the number of projects, the number of new products, the time of introduction and number of new technologies, the number of employees in the field of $\mathrm{R} \& \mathrm{D}$, etc. In other words, the result of the operation of the knowledge management system, the absorption capacity is not considered to be sufficient weighting feature. However, it is noteworthy that a critical point in the functioning of the knowledge management system, the issue of knowledge distribution, is the subject of research in the model. 
Measured and unmeasured elements of intellectual capital

\begin{tabular}{|c|c|c|}
\hline \multicolumn{3}{|c|}{ Intellectual capital } \\
\hline Human capital & Human capital & Human capital \\
\hline Expertise & Organisational culture & Relationship with clients \\
\hline Practical experience & $\begin{array}{l}\text { Quality of cooperation and } \\
\text { communication within the organisation }\end{array}$ & Relationship with suppliers \\
\hline Social competences & IT infrastructure, software and hardware & Relationship with investors \\
\hline Motivation & $\begin{array}{l}\text { Knowledge transfer and knowledge } \\
\text { preservation }\end{array}$ & $\begin{array}{l}\text { Relationship with external } \\
\text { educational institutions }\end{array}$ \\
\hline Leadership competences & $\begin{array}{l}\text { R\&D infrastructure related to product } \\
\text { innovation }\end{array}$ & $\begin{array}{l}\text { Acquisition of external } \\
\text { knowledge }\end{array}$ \\
\hline $\begin{array}{l}\text { Personal knowledge and } \\
\text { competences }\end{array}$ & $\begin{array}{l}\text { R\&D infrastructure related to process } \\
\text { innovation }\end{array}$ & Social responsibility \\
\hline $\begin{array}{l}\text { Continuous } \\
\text { training }\end{array}$ & Organisational structure & The corporate image \\
\hline Training of new entrants & Organisational processes & $\begin{array}{l}\text { Relationship with other social } \\
\text { and economic participants }\end{array}$ \\
\hline $\begin{array}{l}\text { Participation in higher } \\
\text { education }\end{array}$ & $\begin{array}{l}\text { Application of info-communication } \\
\text { technologies }\end{array}$ & \\
\hline Participation in other education & $\begin{array}{l}\text { Organisational forms that support } \\
\text { learning }\end{array}$ & \\
\hline
\end{tabular}

Source: Based on Cedefop 2012:23 own construction.

The relationship speaks for itself, knowledge distribution, joined-up thinking, brainstorming, team work, etc. are fundamental conditions for innovation. This is justified by the term knowledge management appearing at the bottom level of the innovation pyramid, which also appears as one of the conditions according to the thinking of the creators of the pyramid (Galeitzke et al., 2018). At the same time, an interesting shortcoming of the model is that it does not qualify another fundamental condition of the operation of the knowledge management system, namely, the quality of the IT background support. This is a clear hallmark of the failure to exploit the potential of artificial intelligence (Koehler, 2018).

Estimating the company's innovation ability that qualifies the results of relationships is static information. Development or failure can be evaluated only on the basis of results of annual surveys. The aim is to have a method that not only provides information for company management as a benchmark but also outlines the path of progress. The state-of-the-art IT solution, artificial intelligence provides the basis for this, which, in the form of a self-teaching system, continuously provides information that dynamically indicates successful innovation, or induces withdrawal in case of a failed initiative (Makray-Rozsas, 2016).

The artificial intelligence support to be used for the establishment and operation of a successful innovation forecasting system must meet the following requirements:

- an appropriate work-flow management that tracks innovation from the first idea to the launch of the product/service in the market, measuring and recording all important indicators, results and related processes,

- the use of IT security applications is of paramount importance, as they represent innovation results, patents, know-hows, ideas under copyright, and business secrets of firms, 
- a strict and comprehensive regulatory gate-stage process system that guarantees compliance with the procedures, informing decision-makers in time, in the right manner and scope, and their approval for stepping to the next phase of development,

- finally, for the appropriate mapping of customisability, company organisation and decisionmaking processes, innovation procedures, efficient operation of innovation activity.

Based on all these, the randomness or even unpredictability of innovation success can be clearly ruled out, on the contrary: it seems that after certain preparations the success of innovation is guaranteed and quite accurately predictable. It is becoming increasingly evident that approaching the examination of innovation potential, the success of innovation from any sides, all researchers and experts prefer full-range innovation-control functionality built on high-level IT systems, the so-called holistic innovation management systems.

Thus, the success of the future is innovation intelligence, which, built on the above logic, exploiting the self-teaching ability of the system, means an AI-supported solution that can rightly be called a system based on holistic innovation intelligence. This theoretical consideration and the latest research suggest that foreseeable innovation success and its opposite, predictable innovation failure exist. To the critical question, 'how', the recently developed and published AI-supported solution provides the answer (Kasa \& Guban, 2019).

\section{DISCUSSION - THE MANAGERIAL DECISION}

The last step of Figure 1 presented at the beginning of the chapter on theory is the making of the managerial and highest level decision that determines the strategy's further orientation by assessing the risk of innovation success or failure. Thus, the presented logic is completed, which clearly proves the close relationship between $\mathrm{KM}$ and $\mathrm{AI}$ in practice as well, focussing on the role of innovation as knowledge development that determines organisational success.

The strategic and organisational goals of an organisation and the concept of the development of a company are determined by managerial decisions based on the knowledge of the management. Decisions are the results of reactive and proactive thinking, and the application of thinking strategies plays a key role in their quality. Ensuring quality decision is in close relationship with the quantity and relevance of the data collected, so at this point, the tools of artificial intelligence can be an excellent help. An organisation operating in a given economic environment can use this to define the knowledge necessary for achieving strategic goals, and to provide it through the process of knowledge creation.

Through the developmental phases of knowledge management, Velencei et al (2019) defines the process of business decision making as follows. In his view, there are no sharp boundaries between developmental phases, and sometimes even decades of overlaps can be found. The first phase is the "bera", which was characterised by possession, the second is the "t-era", which was characterised by typification and standardisation, and the "e-era" is today's business environment. For management and organisational functioning in the e-era, it is important to anchor so-called e-poles that cover the new environment of business decision making. The three poles are: trust, transfunction and network. This viewpoint is closely related to the networked thinking and direction of development supported by artificial intelligence.

So the future is determined by smart tools, building the digital network where humans, devices, content and service are intertwined. We have been facing the constant growth of data for years that significantly changes management thinking. As companies change along with technological development, the focus has broadened from result management to supporting for management decisions (Belas et al, 2015). Not all data is valuable, but its potential is a critical resource for organisations. The challenge is to 
convert huge amounts of data into valuable information that can be used in a proactive way in decision making. Data collection and analysis support the rationality of managerial strategic decisions, as already mentioned in the chapter on strategy (Belas et al, 2020).

Digitisation can play a significant role in the adaptation, transformation processes of large companies (Antikainena et al., 2018), and IT-supported knowledge management enables the development and exploitation of operational efficiency and innovation abilities through synergies and information processing capabilities (Nonaka et al., 2014; Kettinger et al., 2015).

\section{CONCLUSION - ADDED VALUE OF THE STUDY}

The logic presented above frames the synergy of knowledge management and artificial intelligence, the business significance of their cohesion, starting from the business model, through the strategy, to managerial decisions related to the future development needs that determine the organisation's market success. The framework provides a novel approach to relationships already explored in literature. Another new approach is the extension of the elements of the innovation model measured so far with the missing parameters, based on the elements of knowledge management and intellectual capital. Measuring this extended model with the support of artificial intelligence, and its application to forecasting opens up perspectives for the precise determination of the future development direction of organisations.

The limitations of the research are to be found in the absence of practical usability testing. Our primary aim was to compile a model that defined the above described framework with the most important organisational processes in mind. Then, in the next step, by exploiting the capabilities of artificial intelligence, to define the core values of a future estimation procedure that will fundamentally influence market success. Finally, building on this, so as to justify the supporting role of artificial intelligence, to create a database that in reality makes it possible for organisations to judge the viability of future investments with the help of reasonable decisions. There has not had the opportunity to test this theoretical train of thought in practice. The author hopes to be able to report on this in a future study.

\section{ACKNOWLEDGEMENT}

This work was supported by the TKP2020-NKA-10 project financed under the 2020-4.1.1-TKP2020 Thematic Excellence Programme by the National Research, Development and Innovation Fund of Hungary.

\section{REFERENCES}

Alani, E., Kamarudin, S., Alrubaiee, L., \& Tavakoli, R. (2019). A model of the relationship between strategic orientation and product innovation under the mediating effect of customer knowledge management. Journal of International Studies, 12(3), https://doi.org/10.14254/2071-8330.2019/12-3/19

Anklam, P. (2009). Ten years of net work. The Learning Organization, 16(6), $415-426$. https://doi.org/10.1108/09696470910993909

Antikainena, M., Uusitaloa, T. \& Kivikytö-Reponena, P. (2018). Digitalisation as an Enabler of Circular Economy, Procedia CIRP, 73, pp. 45-49. https://doi.org/10.1016/j.procir.2018.04.027

Arsawan, I., Wirga, I. W., Rajiani, I., \& Suryantini, N. P. S. (2020). Harnessing knowledge sharing practice to enhance innovative work behavior: the paradox of social exchange theory. Polish Journal of Management Studies, 21.

Avdeenko, T. V., Makarova, E.S. \& Klavsuts I.L. (2016). Artificial intelligence support of knowledge transformation in knowledge management systems, in: Proceedings of 13th International Scientific-Technical Conference on

Actual Problems of Electronics Instrument Engineering (APEIE).

https://doi.org/10.1109/APEIE.2016.7807053 
Balcerak, A., \& Woźniak, J. (2021). Reactions to some ICT-based personnel selection tools. Economics and Sociology, 14(1), 214-231. doi:10.14254/2071- 789X.2021/14-1/14

Basten, D., Haamann, T. (2018). Approaches for Organizational Learning: A Literature Review, SAGE Open - Literature Review, 7-9. 1-20. https://doi.org/10.1177/2158244018794224

Belas, J., Amoah, J., Petráková, Z., Kliuchnikava, Y. \& Bilan, Y. (2020). Selected Factors of SMEs Management in the Service Sector. Journal of Tourism and Services, 21(11), 129-146. https://doi.org/10.29036/jots.v11i21.215

Belás, J., Bilan, Y., Ključnikov, A., Vincúrová, Z. \& Macháček, J. (2015). Actual problems of business risk in SME segment. Case study from Slovakia. International Journal of Entrepreneurial Knowledge, 3(1), 46-56. https://doi.org/10.37335/ijek.v3i1.26

Bencsik, A. (2016). Knowledge Management Initiatives and Strategies in Small and Medium Enterprises, IGI Global, ISBN 9781522516422 https://doi.org/10.4018/978-1-5225-1642-2

Bencsik, A. \& Filep, B. (2016). Relationship between Knowledge Management and Innovation, in: Bencsik (eds.) Knowledge Management Initiatives and Strategies in Small and Medium Enterprises, IGI Global, pp. 67-90.

Bencsik, A., Tóbiás Kosár, S. \& Machová, R. (2018). Corporate Culture in Service Companies that Support Knowledge Sharing. Journal of Tourism and Services, 9(16), 7-13. https://doi.org/10.29036/jots.v9i16.41

Bilan Y., Mishchuk, H., Roshchyk, I. \& Joshi, O. (2020). Hiring and retaining skilled employees in SMEs: problems in human resource practices and links with organizational success. Business: Theory and Practice, 21(2), 780-791. DOI: https://doi.org/10.3846/btp.2020.12750

Bilan, Y., Mishchuk, H., Samoliuk, N., \& Grishnova, O. (2019). ICT and Economic Growth: Links and Possibilities of Engaging. Intellectual Economics, 13(1). DOI: https://doi.org/10.13165/IE-19-13-1-07

Cappellari, G., Welter, C. V. N., Hermes, L. C. R., \& Sausen, J. O. (2019). Absorptive capacity: Components and organizational mechanisms for its development. Revista de Administração Mackenzie, 20(6). https://doi.org/10.1590/1678-6971/eRAMD190028

Cedefop (2012). Learning and innovation in enterprises, Research Paper No 27, Publications Office of the European Union.

Cockburn, I.M., Henderson, R. \& Stern, S. (2018). The Impact of Artificial Intelligence on Innovation, Working Paper 24449 Retrieved from http://www.nber.org/papers/w24449 National Bureau of Economic Research.

Cornell University, INSEAD and WIPO (2016). The Global Innovation Index 2016: Winning with Global Innovation, Ithaca, Fontainebleau, and Geneva.

Csizmadia, P. (2015). A szervezeti innováció és tudásfelhasználás mintái a magyar gazdaságban, [Organisational Innovation and Knowledge Usage in the Hungarian Economy] PhD thesis, Corvinus University.

Deloitte (2016). Artificial Intelligence Innovation Report, Springwise, Retrieved from https://www2.deloitte.com/content/dam/Deloitte/at/Documents/human-capital/artificial-intelligenceinnovation-report.pdf

Engel, K., Diedrichs, E. \& Ruppert, M., (2014) Ansätze zur Entwicklung von innovationsgetriebenem Unternehmertum, in: Innovation - Innovationstreiber für Wirtschaft, Wissenschaft, Politik und Gesellschaft Jabrbuch, A.T. Kearney Düsseldorf pp. 20-24. Retrieved from www.improve-innovation.eu

Ertel, W. (2017). Introduction to Artificial Intelligence, Springer International Publishing, https://doi.org/10.1007/978-3-319-58487-4

Forgang, W.G. (2015). Strategy-specific Decision Making: A Guide for Executing Competitive Strategy: A Guide for Executing Competitive Strategy, Routledge.

Galeitzke, M., Steinhöfel, E., Orth, R. \& Kohl, H. (2017). Intellectual Capital-Driven Technology and Innovation, Management. International Journal of Innovation and Technology Management, 14(5), 1750028-1 - 1750028-26. http://dx.doi.org/ 10.1142/S0219877017500286

George, D., Lehrach, W., Kansky, K., Lázaro-Gredilla, M., Laan, C., Marthi, B., Lou, X., Meng, Z., Liu, Y., Wang, H., Lavin, A. \& Phoenix, D.S. (2017). A generative vision model that trains with high data efficiency and breaks text-based CAPTCHAs, Science, 358(6368), 1-19. https://doi.org/10.1126/science.aag2612

Guban, M., Kasa, R., Takacs, D. \& Avornicului, M. (2019). Trends of Using Artificial Intelligence nn Measuring Innovation Potential, Management and Production Engineering Review, 10(2), 3-15. http://dx.doi.org/10.24425/mper.2019.129564 
Haar, P. (2018). Measuring innovation: A state of the science review of existing approaches, Intangible Capital, 14(3), 409-428.

Haenlein, M. \& Kaplan, A. (2019). A brief history of artificial intelligence: On the past, present, and future of artificial intelligence. California Management Review, 61(4), https://doi.org/10.1177/0008125619864925

Hanako, A. (2016). Artificial Intelligence and Knowledge Management. Willford Press.

Jaina, A.K., Nandakumarb, K. \& Ross, A. (2016). 50 years of biometric research: Accomplishments, challenges, and opportunities, Pattern Recognition Letters. 79(8), 80-105.

Kasa, R. (2018). Neurális hálók alkalmazásának lehetőségei innovációs teljesítmény mérésére. Logisztika - Informatika - Menedzsment, 2(2), 60-73. https://doi.org/10.29177/LIM.2018.1.60

Kasa, R. \& Guban, M. (2019). A new method for measuring innovation performance, In: International Conferenceon Economics and Business Management - ICEBM Cluj-Napoca, Proceedings, p. 1.

Kazuo, Y. (2017). How artificial intelligence will change HR. People \& Strategy, 40(3), Summer 2017, 42.

Kettinger, W.J., Li, Y., Davis, J.M. \& Kettinger, L. (2015). The roles of psychological climate, information management capabilities, and IT support on knowledge-sharing: an MOA perspective, European Journal of Information Systems, 24(1), 59-75. https://doi.org/10.1057/ ejis.2013.25

Koehler, J. (2018). Business Process Innovation with Artificial Intelligence: Levering Benefits and Controlling Operational Risks. European Business \& Management,4(2), 55-66. https://doi.org/10.11648/j.ebm.20180402.12

Kuo, K. (2019). Deep Triangle: A Deep Learning Approach to Loss Reserving, Risks 7(3), 97.https://doi.org/10.3390/risks7030097

Lemaignan, S., Warniera, M., Sisbota, A., Clodica, A. \& Alami, R. (2016) Artificial cognition for social human-robot interaction: An implementation, Artificial Intelligence, 247, 45-69. https://doi.org/10.1016/j.artint.2016.07.002

Lesniak, A. \& Zima, K. (2018). Cost Calculation of Construction Projects Including Sustainability Factors Using the Case Based Reasoning (CBR) Method, Sustainability. 10(5), 1608. https://doi.org/10.3390/su10051608

Liu, R. Simon, E., Amann, B. \& Gancarski, S. (2020). Discovering and merging related analytic datasets, Information Systems Journal, 91, 101495. https://doi.org/10.1016/j.is.2020.101495

Makray-Rozsas, A. (2016). Az innováció előreláthatósága: mítosz vagy valóság? Retrieved from http://kamaraonline.hu/cikk/az-innovacio-elorelathatosaga-mitosz-vagy-valosag

Marks, D. (2016). Thoughts on the SAP Digital Boardroom Retrieved from https://blogs.sap.com/2016/07/06/thoughts-on-the-sap-digital-board-room/

Masoomzadeh, A., Zakaria, N. W. W., Masrom, M., Streimikiene, D., \& Tavakoli, R. (2019). Organizational Innovation Factors, Capabilities and Organizational Performance in Automotive Industry. Montenegrin Journal of Economics, 15(3), 83-100.

Mittal, S., Khan, M.A., Romero, D. \& Wuest, T. (2019). Smart manufacturing: Characteristics, technologies and enabling factors, Journal of Engineering Manufacture. 233(5), 1342-1361. https://doi.org/10.1177/0954405417736547

Mura, L. (2020). Marketing Management of Family Businesses: Results of Empirical Study. International Journal of Entrepreneurial Knowledge, 8(2), 56-66. https://doi.org/10.37335/ijek.v8i2.118

Nepelski, D. \& Van Roy, V. (2018). Innovation Radar Identifying the maturity of innovations in EU-funded research and innovation projects, Directorate-General for Communications Networks, Content and Technology, European Commission https://doi.org/10.13140/RG.2.2.35933.72167

Nonakaa, I., Kodamab, M., Hirosec, A. \& Kohlbacher, F. (2014). Dynamic fractal organizations for promotingknowledge-based transformation - A new paradigmfor organizational theory, European Management Journal, 32(1), 137-146. http://dx.doi.org/10.1016/j.emj.2013.02.003

Probst, G., Raub,S. \& Romhardt, K. (2006). Wissen Managen, Wie Unternehmen ibre wertvollste Ressource optimal nutzen. Wiesbaden, Gabler GmbH,

Pushpa, R. (2019) Artificial Intelligence and Knowledge Management - Understanding how they are linked, Retrieved from https://www.linkedin.com/pulse/artificial-intelligence-knowledge-management-how-linked-pushpa/

Rhem, A. J. (2017) The Connection between Artificial Intelligence and Knowledge Management, KM Institute, Retrieved from https://www.kminstitute.org/blog/connection-between-artificial-intelligence-and-knowledgemanagement 
Ruparel, N., \& Choubisa, R. (2020). Knowledge hiding in organizations: A retrospective narrative review and the way forward. Dynamic Relationships Management Journal, 9-22. https://doi.org/10.17708/DRMJ.2020.v09n01a01

Sanzogni, L. Guzman, G. \& Busch, P. (2017). Artificial intelligence and knowledge management: questioning the tacit dimension, Prometheus, 35(1), 37-56. http://dx.doi.org/10.1080/08109028.2017.1364547

Seriani, S., Gallina, P., Scalera, L. \& Lughi, V. (2018). Development of n-DoF Preloaded Structures for Impact Mitigation in Cobot, Journal of Mechanisms and Robotics. 10(5), 051009. https://doi.org/10.1115/1.4040632

Shabbir, J. \& Anwer, T. (2015).Artificial Intelligence and its Role in Near Future, Journal of Latex Class Files, 14(8), 1 11.

Silva de Garcia, P., Oliveira, M., \& Brohman, K. (2020). Knowledge sharing, hiding and hoarding: how are they related? Knowledge Management Research \& Practice, https://doi.org/10.1080/14778238.2020.1774434

Stachova, K., Stacho Z., Raišienè, A.G. \& Barokova, A. (2020). Human resource management trends in Slovakia. Journal of International Studies, 13(3), https:/ / doi.org/10.14254/2071-8330.2020/13-3/21

Syed V. A. (2017) Affirmative Knowledge and Positive Human Nature, Evolution of Knowledge Science, Myth to Medicine: Intelligent Internet-Based Humanist Machines, Chapter 3. pp. 35-46. Elsevier https://doi.org/10.1016/B978-0-12805478-9.00003-0

Teece, D.J. (2016). Dynamic capabilities and entrepreneurial management in large organizations: Toward a theory of the (entrepreneurial) firm, European Economic Review, 86, 202-216. https://doi.org/10.1016/j.euroecorev.2015.11.006

Upshall, M. (2019). Using AI to Solve Business Problems in Scholarly Publishing, Insights32(1), 13. http://doi.org/10.1629/uksg.460

Velencei, J., Szeghegyi, A., Baracskai, Z. \& Bokayne Andrasko B. (2019). Modeling the intuitive decision-maker's mindset, Acta Polytechnica Hungarica, 16(3), 227-240.

Wijaya, P., \& Suasih, N. N. (2020). The effect of knowledge management on competitive advantage and business performance: A study of silver craft SMEs. Entrepreneurial Business and Economics Review, 8(4), 105-121. https://doi.org/10.15678/EBER.2020.080406

Zamir, Z (2019). The impact of knowledge capture and knowledge sharing on learning, adaptability, job satisfaction and staying intention. International Journal of Entrepreneurial Knowledge, 7(1), 46-64. https://doi.org/10.2478/ijek2019-0004 